\title{
High-flow nasal cannula therapy, factors affecting effective inspired oxygen fraction: an experimental adult bench model
}

\author{
Frédéric Duprez ${ }^{1,5} \cdot$ C. de Terwangne ${ }^{2,7} \cdot$ V. Bellemans ${ }^{1} \cdot$ W. Poncin ${ }^{3} \cdot$ G. Reychler ${ }^{3} \cdot$ A. Sorgente ${ }^{4} \cdot$ G. Cuvelier ${ }^{5}$. \\ S. Mashayekhi ${ }^{1} \cdot$ X. Wittebole ${ }^{6}$
}

Received: 8 May 2021 / Accepted: 25 November 2021 / Published online: 8 December 2021

(c) The Author(s), under exclusive licence to Springer Nature B.V. 2021

\begin{abstract}
Oxygenation through High Flow Delivery Systems (HFO) is described as capable of delivering accurate $\mathrm{F}_{\mathrm{iO2} 2}$. Meanwhile, peak inspiratory flow $\dot{V}_{\mathrm{I}}$ ) of patients with acute hypoxemic respiratory failure can reach up to $120 \mathrm{~L} / \mathrm{min}$, largely exceeding HFO flow. Currently, very few data on the reliability of HFO devices at these high $\dot{V}_{\text {I }}$ are available. We sought to evaluate factors affecting oxygenation while using HFO systems at high $\dot{V}_{\mathrm{I}}$ in a bench study. Spontaneous breathing was generated with a mechanical test lung connected to a mechanical ventilator Servo-i®, set to volume control mode. Gas flow from a HFO device was delivered to the test lung. The influence on effective inspired oxygen fraction of three parameters $\left(\mathrm{F}_{\mathrm{iO} 2} 0.6\right.$, 0.8 , and $1, \dot{V}_{\mathrm{I}}$ from 28 to $98.1 \mathrm{~L} / \mathrm{min}$, and HFO Gas Flows from 40 to $60 \mathrm{~L} / \mathrm{min}$ ) were analyzed and are reported. The present bench study demonstrates that during $\mathrm{HFO}$ treatment, measured $\mathrm{F}_{\mathrm{iO} 2}$ in the lung does not equal set $\mathrm{F}_{\mathrm{iO} 2}$ on the device. The substance of this variation $\left(\Delta \mathrm{F}_{\mathrm{iO} 2}\right)$ is tightly correlated to $\dot{V}_{\mathrm{I}}$ (Pearson's coefficient of 0.94 , p-value $<0.001$ ). Additionally, set $\mathrm{F}_{\mathrm{iO} 2}$ and Flow at HFO device appear to significatively affect $\Delta \mathrm{F}_{\mathrm{iO} 2}$ as well (p-values $<0.001$, adjusted to $\dot{V}_{\mathrm{I}}$ ). The result of multivariate linear regression indicates predictors $\left(\dot{V}_{\mathrm{I}}\right.$, Flow and set $\left.\mathrm{F}_{\mathrm{iO} 2}\right)$ to explain $92 \%$ of the variance of delta $\mathrm{F}_{\mathrm{iO} 2}$ through K-Fold Cross Validation. Moreover, adjunction of a dead space in the breathing circuit significantly decreased $\Delta \mathrm{F}_{\mathrm{iO} 2}$ $(\mathrm{p}<0.01)$. The present bench study did expose a weakness of HFO devices in reliability of delivering accurate $\mathrm{F}_{\mathrm{IO} 2}$ at high $\dot{V}_{\mathrm{I}}$ as well as, to a lesser extent, at $\dot{V}_{\mathrm{I}}$ below equivalent set HFO Flows. Moreover, set HFO flow and set $\mathrm{F}_{\mathrm{IO} 2}$ did influence the variability of effective inspired oxygen fraction. The adjunction of a dead space in the experimental set-up significantly amended this variability and should thus be further studied in order to improve success rate of HFO therapy.
\end{abstract}

Keywords Oxygenation through High Flow Delivery Systems $\cdot$ HFO $\cdot$ HFNC $\cdot$ Inspiratory flow $\cdot$ Minute ventilation · Effective inspired oxygen fraction · Double trunk mask

\section{Abbreviations}

HFO Oxygenation through High Flow System

$\dot{V}_{\text {I }} \quad$ Peak Inspiratory Flow
$\dot{V}_{\mathrm{E}} \quad$ Minute Ventilation

$\mathrm{F}_{\mathrm{iO} 2} \quad$ Inspired oxygen fraction

$\mathrm{sF}_{\mathrm{iO} 2}$ Set inspired oxygen fraction at $\mathrm{HFO}$ device

F. Duprez and C. de Terwangne have contributed equally to the conception, methodology and writing of the present study.

Frédéric Duprez

frederic.duprez@condorcet.be

C. de Terwangne

Christophe_terwangne@ hotmail.com

1 Department of Intensive Care, Centre Hospitalier Epicura, Hornu, Belgium

2 Department of Geriatric Medicine, Cliniques Universitaires Saint-Luc, Brussels, Belgium

3 Department of Internal Medicine, Université Catholique de Louvain, Brussels, Belgium
4 Department of Cardiology, Centre Hospitalier Epicura, Hornu, Belgium

5 Laboratory of Respiratory Physiology, Condorcet School, Tournai, Belgium

6 Département of Intensive Care, UCLouvain, Cliniques universitaires St. Luc, Brussels, Belgium

7 Brussels, Belgium 

$\mathrm{mF}_{\mathrm{i} 02}$ Measured inspired oxygen fraction in the test lung (or effective inspired oxygen fraction)
$\Delta \mathrm{F}_{\mathrm{iO} 2}$ Difference between set inspired oxygen fraction
and measured inspired oxygen fraction

\section{Introduction}

Oxygenation through high flow delivery (HFO) systems has been gaining increasing interest for the last 10 years among intensivists and emergency care physicians, especially in the context of advanced acute respiratory failure resistant to low flow oxygen therapy $[1,2]$. The HFO devices are described as capable of delivering reliable, reproducible and accurate $\mathrm{F}_{\mathrm{iO} 2}$ from 0.21 to 1.0 with flows between 20 and $60 \mathrm{~L} / \mathrm{min}[3,4]$. Hypoxemic critically ill patients do benefit the most of high flow oxygen devices and present with high Minute Ventilation $\left(\dot{V}_{\mathrm{E}}\right)$ and consequently high peak inspiratory flows $\left(\dot{V}_{I}\right)$ [5]. This is especially the case of critically ill patients due to the Coronavirus 2019 disease (SARS-CoV-2). Indeed, despite severe pulmonary damage, the latter patients can maintain quite normal elastic-resistive thoraco-pulmonary characteristics during the first week of respiratory failure [6] thus being often capable of maintaining high $\dot{V}_{\mathrm{E}}$ and $\dot{V}_{\mathrm{I}}$ during a prolonged time [7]. In some cases, the peak inspiratory flow of patients with acute hypoxemic respiratory failure can even reach up to $120 \mathrm{~L} / \mathrm{min}$ [8], largely exceeding HFO flow. At these high $\dot{V}_{\mathrm{I}}$, the assumption is made that atmospheric room air might enter the breathing circuit and dilute the set $\mathrm{F}_{\mathrm{iO} 2}$ from $\mathrm{HFO}$ [3] reducing consequently the effectively delivered $\mathrm{F}_{\mathrm{IO} 2}$.

We firmly believe that a thorough understanding of $\mathrm{F}_{\mathrm{iO} 2}$ stability during HFO therapy is paramount as it is increasingly used in acute respiratory failure severity scores [9] [10] as well as scores predicting the need for intubation [11]. Since HFO is used in very sick hypoxemic patients, with high Respiratory frequency (Rf) and high Tidal Volumes (Vt) due to high oxygen demands and thus approximate $\dot{V}_{\mathrm{I}}$ up to $100 \mathrm{~L} / \mathrm{min}$ [12], such as critically ill SARS-CoV-2 patients, we sought to evaluate the reliability of HFO systems at these higher $\dot{V}_{\mathrm{I}}$.

Therefore, the aim of the study was to analyze the effect of high $\dot{V}_{\mathrm{E}}$ and $\dot{V}_{\mathrm{I}}$ on effective $\mathrm{F}_{\mathrm{IO} 2}$ during HFO treatment in an experimental adult bench model.

Additionally, since previous studies have found that the addition of a surgical mask or a Double Trunk Mask (DTM) (dead space) above HFO nasal cannulas may increase the arterial pressure in oxygen in some hypoxemic patients despite any modification in HFO settings [13, 14], the secondary aim of the study was to evaluate the impact of the addition of a dead space on effective inspired $\mathrm{F}_{\mathrm{iO} 2}$.

\section{Material and methods}

\subsection{Experimental adult model}

The HFO was generated by an Airvo2 TM device (Fisher \& Paykel Health Care, Auckland, New Zealand) through a T piece connector (INTERSURGICAL T-Piece Connector iso 22-DS00586). The $\mathrm{T}$ piece was connected to a mechanical test lung through a single ventilator tubing (iso 22). The first lung was driven by a mechanical ventilator (Servoi ${ }^{\mathrm{TM}}$ Maquet, Getinge group, Getingue, Sweden) (Labelled as Drive Mechanical Ventilator) to simulate a spontaneous breathing pattern.

\subsection{High flow oxygenation device (HFO)}

Gas flow from Airvo2 TM was set at 40, 50 and $60 \mathrm{~L} / \mathrm{min}$ and confirmed by a calibrated flowmeter (SP-304 flow sensorIworx ${ }^{\circledR}$, United States). $\mathrm{F}_{\mathrm{iO} 2}$ was set at $0.6,0.8$ and 1 and confirmed by a calibrated oxygen analyzer (two point calibration, GA-200 Side stream, Gas Analyzer Iworx®, United States) which was connected to a data-acquisition system IX-214 hardware Oxygen analyzer GA-200, first calibrated with room air (21\%) and secondly at $100 \%$ with certified $\mathrm{O}_{2}$ gas coming from an oxygen gas cylinder. To evaluate the dynamic variability of effective inspired oxygen fraction into this bench model during respiratory cycle, the measures of $\mathrm{F}_{\mathrm{iO} 2}$ were performed at two different locations:

(1) Directly into the artificial lung through the $\mathrm{O}_{2}$ port of the second lung (Fig. 1)

(2) Near the T piece (Fig. 1).

When an experimental setting was changed, it was left stabilizing for 3 min prior to measuring. The $\mathrm{F}_{\mathrm{IO} 2}$ was measured for $1 \mathrm{~min}$ and data of the final 3 breaths were extracted. The mean of these three measures is reported.

\subsection{Spontaneous breathing}

Spontaneous breathing was generated in Ambient Temperature and Pressure Saturated (ATPS) conditions with a mechanical test lung (Dual Test Lung-Michigan Instruments, Inc. Grand Rapids Model 5600i) including two independent artificial lungs. The two lung compartments were synchronized with a lung coupling clip, which allowed the first lung to drive the second lung in order to achieve spontaneous breathing simulation. Resistive and Elastic characteristics of Dual Test Lung were: $5 \mathrm{cmH}_{2} \mathrm{O} / \mathrm{L} / \mathrm{sec}$ and $0.06 \mathrm{~L} / \mathrm{cmH}_{2} \mathrm{O}$.

The first lung was driven by a mechanical ventilator Servo-i ${ }^{\mathrm{TM}}$ (Servo i $^{\mathrm{TM}}$ Maquet, Getinge group, Getinge, 




Fig. 1 Set-up of the experimental adult bench model. HFO=High Flow Oxygenation. (*) represents "With Trunk" set up. In this set up, a dead space was added through the adjunction of an ISO 22 tube of $30 \mathrm{~cm}$ of length on the T piece

Sweden) set to volume control mode (descending ramp flow waveform without auto-flow, time pause and inspiratory rise time at $0 \%$, peep of $0 \mathrm{cmH}_{2} \mathrm{O}$, the trigger was set at -10 $\mathrm{cmH}_{2} 0$ in order to avoid self-triggering).

Respiratory frequency (Rf) was set to $10,15,20,25,30$ and 35 breaths/min with an inspiratory time (Ti) to expiratory time $(\mathrm{Te})$ ratio of 0.5 . Tidal Volume was set at $0.7 \mathrm{~L}$ giving $\dot{V}_{\mathrm{E}}$ equal to $7,10.5,14,17.5,21$ and $24.5 \mathrm{~L} / \mathrm{min}$, either $\dot{V}_{\mathrm{I}}$ of $28,42,56.1,70.1,84.1,98.1 \mathrm{~L} / \mathrm{min}$ respectively.

The experiment was duplicated with the adjunction of a supplementary dead space of $0.230 \mathrm{~L}$ (corrugated ISO 22 tube of $30 \mathrm{~cm}$ of length) connected on the T-piece, corresponding to the "With Trunk" set-up (Fig. 1).

\subsection{Statistical analysis}

$\dot{V}_{\mathrm{E}}$ was defined as the product of Vt and Rf. Difference in measured $\mathrm{F}_{\mathrm{iO} 2}\left(\mathrm{mF}_{\mathrm{iO} 2}\right)$ and set $\mathrm{F}_{\mathrm{iO} 2}\left(\mathrm{sF}_{\mathrm{iO} 2}\right)$ was defined as $\Delta \mathrm{F}_{\mathrm{iO} 2}$. Continuous variables are presented as mean $( \pm \mathrm{SD})$. The assessment of the relationship between $\dot{V}_{\mathrm{I}}$ and $\Delta \mathrm{F}_{\mathrm{iO} 2}$ was computed through Pearson's correlation analysis in function of the different variable groups (set HFO Flow and $\mathrm{sF}_{\mathrm{iO} 2}$ ). To define which variables were the most determinant in predicting effective inspired oxygen concentration and $\Delta \mathrm{Fi}_{\mathrm{O} 2}$, forward stepwise multiple linear regression was computed. Variables with a p-value $<0.01$ were entered into the model. Multiple linear regression modelling was computed to evaluate the effects of selected variables $\left(\dot{V}_{\mathrm{E}}, \mathrm{HFO}\right.$ Flow, and $\left.\mathrm{sFi}_{\mathrm{O} 2}\right)$ on $\Delta \mathrm{F}_{\mathrm{iO} 2}$ and effective inspired oxygen fraction. The model was then internally validated with a 10-Fold Cross Validation Procedure.

Differences between groups (with and without Trunk, $\mathrm{sFi}_{\mathrm{O} 2}$ and HFO Flow) were compared through ANCOVA adjusted for $\dot{V}_{\mathrm{I}}$. Normality was assessed using the Shapiro-Wilk test and linearity between the dependent variable $\left(\Delta \mathrm{F}_{\mathrm{iO} 2}\right)$ and the covariate $\left(\dot{V}_{\mathrm{I}}\right)$ was assessed by correlation plots with Pearson's correlation coefficient per studied factor (Trunk, set HFO Flow and $\mathrm{sF}_{\mathrm{iO} 2}$ ).

Throughout analysis, a p-value below 0.01 was considered as statistically significant.

Statistical analysis was performed using R: A Language and Environment for Statistical Computing, R Core Team, Vienna, Austria, 2020, https://www.r-project.org/.

(Used packages emmeans, ggpubr, rstatix, lattice, car, caret).

\section{Results}

The influence of the different variables on $\Delta \mathrm{F}_{\mathrm{iO} 2}$ is demonstrated in Fig. 2; Tables 1 and 2. The experimental set up demonstrated high variation in measured $\mathrm{F}_{\mathrm{iO} 2}\left(\mathrm{mF}_{\mathrm{iO} 2}\right)$ through the respiratory cycle in function of the location of the measurement. At the T-piece, measured $\mathrm{F}_{\mathrm{iO} 2}$ oscillated from $\pm 10 \%$ whereas, at the lung sampling point, this oscillation was around $2-4 \%$. Therefore, further $\mathrm{FiO}_{2}$ measurements were conducted intra-pulmonary. 



Fig. $2 \mathrm{~F}_{\mathrm{iO} 2}$ was measured at T-piece $\mathbf{A}$ and intra-pulmonary (B). Measures at $\mathrm{T}$ piece showed variations up to $10 \%$ of $\mathrm{F}_{\mathrm{IO} 2}$, whereas variations of intra-pulmonary measures were limited to $3 \%$

Table 1 Stepwise Selection Summary

\begin{tabular}{lllll}
\hline Step & Variable & R-Square & Adj. R-Square & RMSE \\
\hline 1 & $\dot{V}_{\mathrm{I}}$ & 0.478 & 0.468 & 7.19 \\
2 & HFO Flow & 0.696 & 0.685 & 5.54 \\
3 & F $_{\mathrm{iO} 2}$ & 0.858 & 0.849 & 3.83 \\
\hline
\end{tabular}

Table 2 Linear regression model: $\Delta \mathrm{F}_{\mathrm{iO} 2} \sim \dot{V}_{\mathrm{I}}+\mathrm{sF}_{\mathrm{iO} 2}+\mathrm{HFO}$ Flow

\begin{tabular}{lcll}
\hline & Coefficients & $95 \% \mathrm{CI}^{\mathrm{a}}$ & $\mathrm{p}$ value \\
\hline$\dot{V}_{\mathrm{I}}$ & 0.28 & $0.24,0.33$ & $<0.001$ \\
$\mathrm{sF}_{\mathrm{iO} 2}$ & 0.24 & $0.18,0.30$ & $<0.001$ \\
HFO Flow & -0.56 & $-0.69,-0.43$ & $<0.001$ \\
\hline
\end{tabular}

${ }^{a} C I=$ Confidence Interval, $\dot{V}_{\mathrm{I}}=$ Peak Inspiratory Flow, $\Delta \mathrm{F}_{\mathrm{iO} 2}=$ difference between measures $\mathrm{F}_{\mathrm{iO} 2}\left(\mathrm{mF}_{\mathrm{iO} 2}\right)$ and $\operatorname{setF}_{\mathrm{iO} 2}\left(\mathrm{sF}_{\mathrm{iO} 2}\right), \mathrm{HFO}=\mathrm{High}$ Flow Oxygenation

The difference $\left(\Delta \mathrm{F}_{\mathrm{iO} 2}\right)$ between measured $\mathrm{F}_{\mathrm{iO} 2}$ and $\mathrm{sF}_{\mathrm{iO} 2}$, is influenced by $\dot{V}_{\mathrm{I}}$, set Flow and $\mathrm{F}_{\mathrm{iO} 2}$ at $\mathrm{HFO}$ (Fig. 4; Table 2).

$\dot{V}_{\mathrm{I}}$ exerted a positive linear relation with $\Delta \mathrm{F}_{\mathrm{iO} 2}$ throughout the different variable groups (set HFO Flows and $\mathrm{sF}_{\mathrm{iO} 2}$ ) with a minimal Pearson's coefficient of 0.94 (p-value $<0.001$ ). The higher $\dot{V}_{\mathrm{I}}$, the more $\Delta \mathrm{F}_{\mathrm{iO} 2}$ increases. This trend is accentuated with the increase of $\mathrm{sFi}_{\mathrm{O} 2}$ and the decrease of HFO Flow (Fig. 3), reaching a maximum $\Delta \mathrm{F}_{\mathrm{iO} 2}$ of $44 \%$ at $\dot{V}_{\mathrm{I}}$ of $\pm 98 \mathrm{~L} / \mathrm{min}, \mathrm{sFi}_{\mathrm{O} 2}$ at 1 with a $\mathrm{HFO}$ flow of $\pm 40 \mathrm{~L} / \mathrm{min}$. For each curve without trunk reported in Fig. 3, there seems to be a threshold under which $\Delta \mathrm{F}_{\mathrm{iO} 2}$ variations are less important.
This threshold matches the point at which $\dot{V}_{\text {I }}$ equalize HFO Flow (intersection of dashed line and without trunk curve in Fig. 3).

Stepwise selection model (Table 1) showed $\dot{V}_{\mathrm{I}}$ to be the most influencing variable of $\Delta \mathrm{F}_{\mathrm{iO} 2}$. The model did improve significantly with the adjunction of HFO Flow and set $\mathrm{F}_{\mathrm{iO} 2}: \mathrm{R}^{2}$ increases, and a Root-Mean-Square Error (RMSE) decreases at each step.

The model, with $\Delta \mathrm{F}_{\mathrm{iO} 2}$ as dependent variable, based on the stepwise selection model (Table 2) yielded a $\mathrm{R}^{2}$ of 0.849 and a RMSE 3.83. This could be improved with a 10-Fold Cross Validation procedure to a $\mathrm{R}^{2}$ of 0.92 and a RMSE of 3.76. All three variables $\left(\dot{V}_{\mathrm{E}}, \mathrm{sF}_{\mathrm{iO} 2}\right.$, and HFO Flow) are highly significant in predicting $\Delta \mathrm{F}_{\mathrm{iO} 2}(\mathrm{p}<0.001)$.

Effects on $\Delta \mathrm{F}_{\mathrm{iO} 2}$ of HFO Flow and $\mathrm{sF}_{\mathrm{iO} 2}$, adjusted to $\dot{V}_{\mathrm{I}}$ (estimated marginal means), is shown in Fig. 4. Set $\mathrm{F}_{\mathrm{iO} 2}$ significantly modified $\Delta \mathrm{F}_{\mathrm{iO} 2}$ (ANCOVA adjusted for $\dot{V}_{\mathrm{I}}$, $\mathrm{F}=35.45 \mathrm{p}<0.001)$. On the other hand, HFO Flow also did significantly change $\Delta \mathrm{F}_{\mathrm{iO} 2}$ (ANCOVA adjusted for $\dot{V}_{\mathrm{E}}$, $\mathrm{F}=48.14, \mathrm{p}<0.001)$.

When a trunk was added to the T-piece, $\Delta \mathrm{F}_{\mathrm{iO} 2}$ did significantly decrease at each level of $\mathrm{sF}_{\mathrm{iO} 2}$ (Tukey's adjusted p-value <0.01) (Fig. 5A). $\Delta \mathrm{F}_{\mathrm{iO} 2}$ did also decrease at each different set Flow at high oxygenation device with adjunction of a trunk (Tukey's adjusted p-value <0.01) (Fig. 5B).

\section{Discussion}

The present bench study demonstrates that during HFO treatment, measured $\mathrm{F}_{\mathrm{iO} 2}$ in the lung does not always equal set $\mathrm{F}_{\mathrm{iO} 2}$ on the device. The substance of this variation 


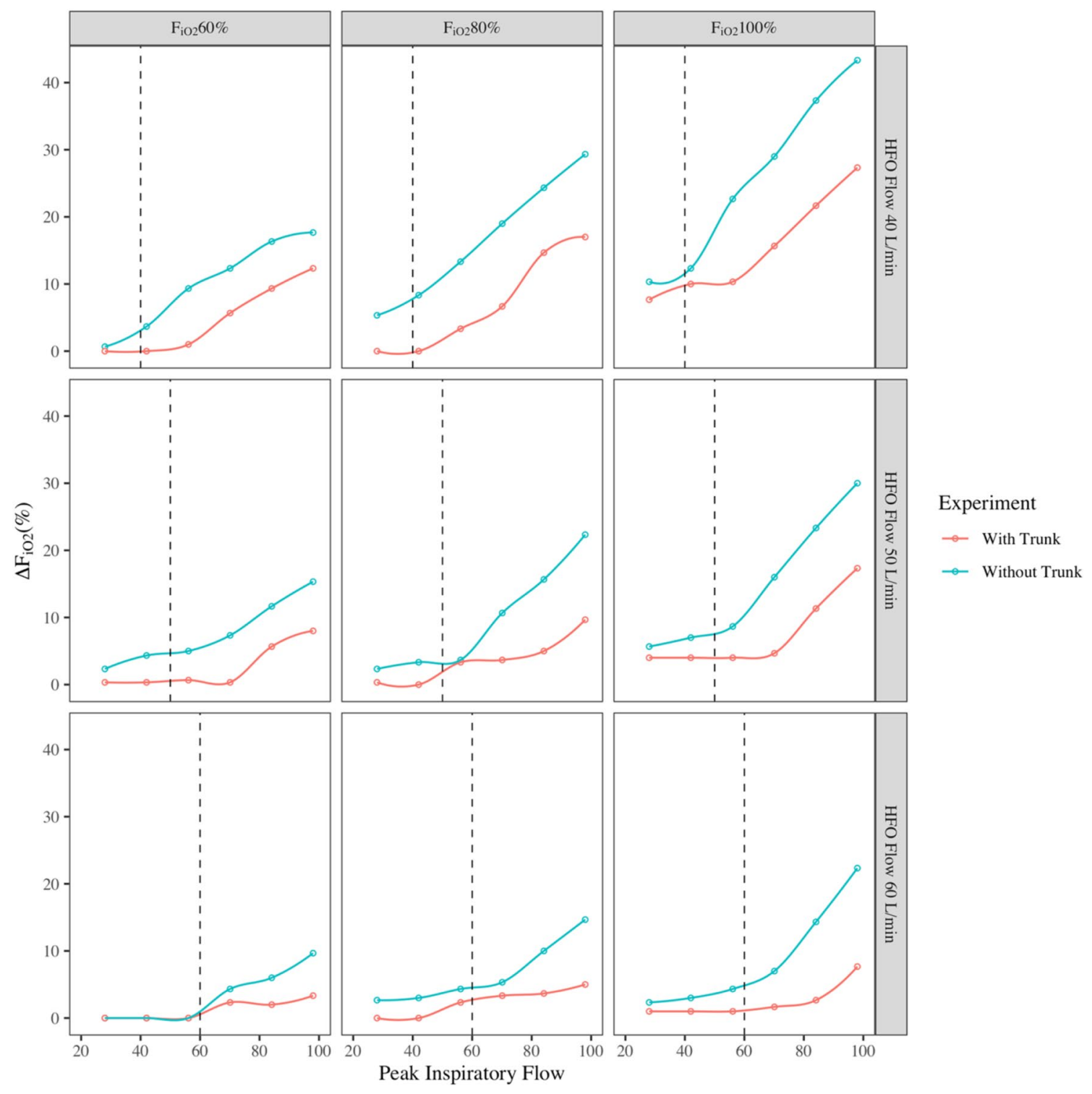

Fig. $3 \Delta \mathrm{F}_{\mathrm{iO} 2}$ in function of Peak Inspiratory Flow grouped by the different experimental variables $\left(\mathrm{sF}_{\mathrm{iO} 2}\right.$ and $\mathrm{HFO}$ Flow). The blue curve represent $\Delta \mathrm{F}_{\mathrm{iO} 2}$ variations without adjunction of a dead space (Without Trunk) as the red curve does represent $\Delta \mathrm{F}_{\mathrm{iO} 2}$ with the adjunction

seems to be directly correlated to $\dot{V}_{\mathrm{I}}$ value. Indeed, as $\dot{V}_{\mathrm{I}}$ increases, $\Delta \mathrm{F}_{\mathrm{iO} 2}$ amplifies. Additionally, $\mathrm{sF}_{\mathrm{iO} 2}$ and Flow at HFO device appear to significatively affect this difference. The result of the linear regression indicated predictors $\left(\dot{V}_{\mathrm{I}}\right.$, Flow and set $\mathrm{F}_{\mathrm{iO} 2}$ ) to explain $92 \%$ of the variance of $\Delta \mathrm{F}_{\mathrm{iO} 2}$ through K-Fold Cross Validation. Interestingly, adjunction of a dead space in the breathing circuit did significantly decrease $\Delta \mathrm{F}_{\mathrm{iO} 2}$.

At first, this study shows important oscillations in $\mathrm{F}_{\mathrm{iO} 2}$ measures through the respiratory cycle in function of the location of the measurements in the experimental set-up of a dead space (With Trunk). $\Delta \mathrm{F}_{\mathrm{iO} 2}$ rises when Flows are lower and set $\mathrm{F}_{\mathrm{iO} 2}$ is high. Dashed line represents Peak Inspiratory Flow equal to HFO Flow

(Fig. 1). To simulate physiological conditions, i.e. open mouth or inevitable leaks around the nasal cannula, a T-piece was mounted in the experimental set up. $\mathrm{F}_{\mathrm{iO} 2}$ measurements at the T-piece present oscillation of up to $10 \%$ in $\mathrm{F}_{\mathrm{iO} 2}$ through the respiratory cycle in comparison with oscillations of up to $4 \%$ of "intra-pulmonary" measurements (Fig. 1). This first finding demonstrates presence of air blending in this part of the circuit, that stabilizes when arriving in the lungs. Analysis in the present study was therefore carried out on stabilized intra-pulmonary $\mathrm{F}_{\mathrm{iO} 2}$ measurements, as recommended by the manufacturer of the Dual Test Lung. 


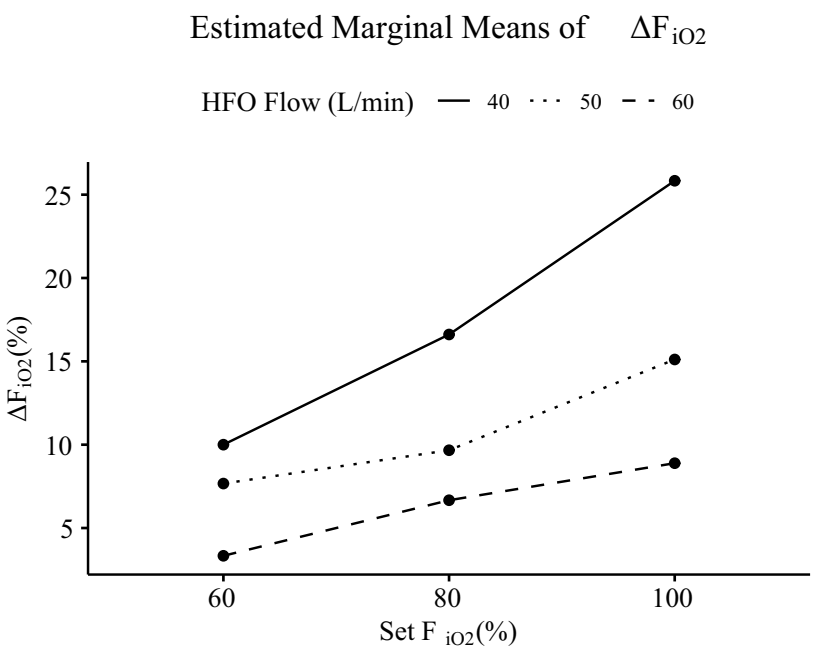

Fig. 4 Estimated Marginal Means of $\Delta \mathrm{F}_{\mathrm{iO} 2}$, after adjustment of $\dot{V}_{\mathrm{I}}$, in function of $\mathrm{sF}_{\mathrm{iO} 2}$, at HFO Flow 40,50 and $60 \mathrm{~L} / \mathrm{min} . \Delta \mathrm{F}_{\mathrm{iO} 2}=$ Difference between Set $\mathrm{F}_{\mathrm{iO} 2}\left(\mathrm{sF}_{\mathrm{iO} 2}\right)$ and measured $\mathrm{F}_{\mathrm{iO} 2}\left(\mathrm{mF}_{\mathrm{iO} 2}\right)$, $\mathrm{HFO}=$ High Flow Oxygenation. Differences between flows are statistically significant (cfr ANCOVA result). At different levels of Set $\mathrm{F}_{\mathrm{iO} 2}$, differences in $\Delta \mathrm{F}_{\mathrm{iO} 2}$ is most important with $\mathrm{HFO}$ flow at $40 \mathrm{~L} /$ $\min$

Through the analysis of these measurements, important differences were found between $\mathrm{sFiO}_{2}$ and $\mathrm{mF}_{\mathrm{iO} 2}\left(\mathrm{sF}_{\mathrm{iO} 2}\right.$ $\mathrm{mF}_{\mathrm{iO} 2}=\Delta \mathrm{F}_{\mathrm{iO} 2}$ ) at different $\dot{V}_{\mathrm{I}}$, Flow and set $\mathrm{F}_{\mathrm{iO} 2} . \dot{V}_{\mathrm{I}}$ was the most significant variable influencing $\Delta \mathrm{F}_{\mathrm{iO} 2}$ and exerted a positive linear relation with the latter. This finding accentuates the purpose of our study which assessed the effects of high $\dot{V}_{\mathrm{E}}$ and $\dot{V}_{\mathrm{I}}$ while other studies did limit this variable to physiologic "resting" values [3].

Meanwhile, there seems to be a threshold of $\dot{V}_{\mathrm{I}}$ under which $\Delta \mathrm{F}_{\mathrm{iO} 2}$ does diverge less. It was indeed previously

A Estimated Marginal Means of $\Delta \mathrm{F}_{\mathrm{iO} 2}$

$$
\text { - With Trunk - - Without Trunk }
$$

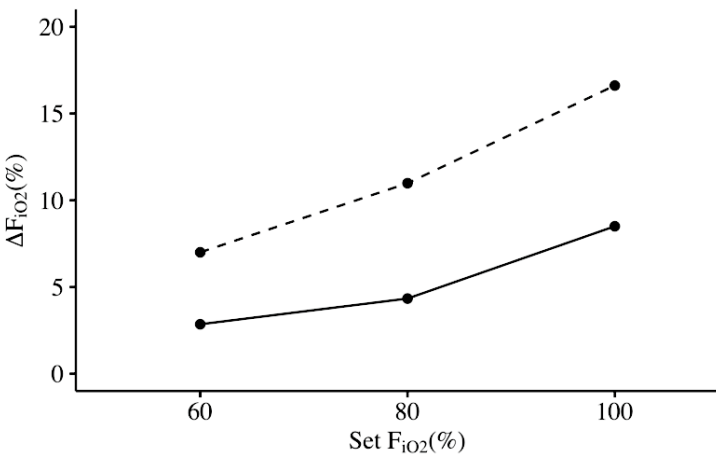

Fig. 5 Estimated Marginal Means of $\Delta \mathrm{F}_{\mathrm{iO} 2}$ with and without adjunction of a trunk (additional dead space) at different $\mathrm{sF}_{\mathrm{iO} 2} \mathbf{A}$ and different HFO Flows (B). At each level of $\mathrm{sF}_{\mathrm{iO} 2}$ and HFO Flow, difference hypothesized that once $\dot{V}_{\mathrm{I}}$ do exceed HFO Flow of the High Flow Oxygenation Device, air blending between high oxygenated air from HFO and room air from the mouth or leaks do occur and could thus decreases actual delivered $\mathrm{F}_{\mathrm{iO} 2}$ [3]. When $\dot{V}_{\mathrm{I}}$ does exceed HFO Flow, depression happen inside the circuit, which consequently causes a suction effect inside the upper airways. Entrained room-air arriving from the mouth or leaks around the nasal canula (the $\mathrm{T}$ piece in our experimental set up), blend with oxygenated air from HFO, thus decreasing $\mathrm{F}_{\mathrm{iO} 2}$ of inspired HFO flow.

From our data we can indeed extrapolate a breaking point corresponding to the point where $\dot{V}_{\mathrm{I}}$ and HFO Flow equalizes. This point can be found at the intersection of the dashed line ( $\dot{V}_{\mathrm{I}}=$ HFO Flow $)$ and the curve "Without Trunk" in Fig. 3. If above this point $\Delta \mathrm{F}_{\mathrm{iO} 2}$ looks clear and was expected, it seems however that below this point, air blending does also occur.

To explain the latter, we make the assumption of a possible Bernoulli effect in the upper airways during inspiration when $\dot{V}_{\mathrm{I}}$ does not exceed HFO Flow. Laminar flux creates depression in the circuit and thus an air suction effect coming from the T-piece (anatomically comparable with the mouth or leaks around nasal cannula). Air blending will occur and generate a $\Delta \mathrm{F}_{\mathrm{iO} 2}$ which value will vary on $\mathrm{sF}_{\mathrm{iO} 2}$ and $\mathrm{HFO}$ Flow (Fig. 3.). Indeed, $\Delta \mathrm{F}_{\mathrm{iO} 2}$ will increase when $\mathrm{sF}_{\mathrm{iO} 2}$ is set at higher values, and at lower HFO Flows.

The rational principle behind these different findings lays on the mathematical air-mixing equation of an air circuit [15]. With the formula of this principle, we simulated and depicted in Fig. 6 the relationship of $\mathrm{F}_{\mathrm{iO} 2}$ calculated through different $\mathrm{sF}_{\mathrm{iO} 2}$ at different Air Flows. Air Flow in this simulation illustrates the flow arising from the suction effect during either assumed Bernoulli effect either $\dot{V}_{\text {I }}$ exceeding HFO Flow. As the mean difference in $\dot{V}_{\text {I }}$

\section{B Estimated Marginal Means of $\Delta \mathrm{F}_{\mathrm{iO} 2}$}

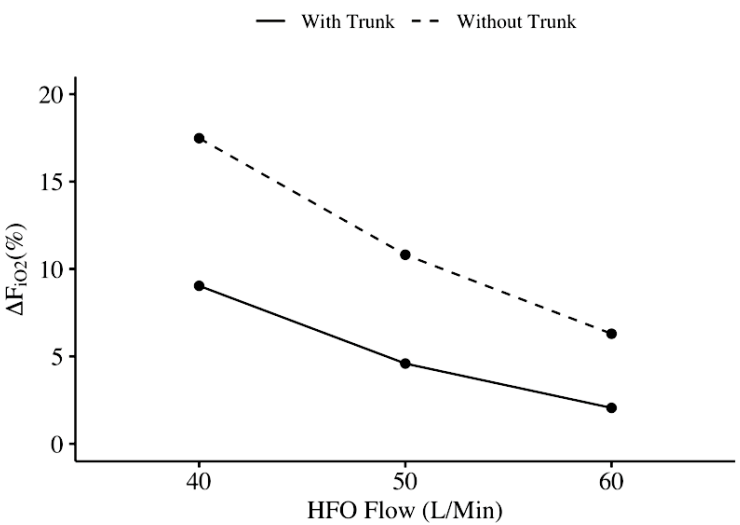

between trunk and without trunk is statistically significant $(\mathrm{p}<0.01)$ with Tukey's adjusted p-values 
Fig. 6 Mathematical estimation of $\Delta \mathrm{F}_{\mathrm{iO} 2}\left(\right.$ Set $\mathrm{F}_{\mathrm{iO} 2}-$ Calculated $\mathrm{F}_{\mathrm{iO} 2}$ ) according to the air-mixing equation of Guillaume et al. Air Flow illustrates the flow arising from the suction effect during either assumed Bernoulli effect either $\dot{V}_{\mathrm{I}}$ exceeding HFO Flow or both

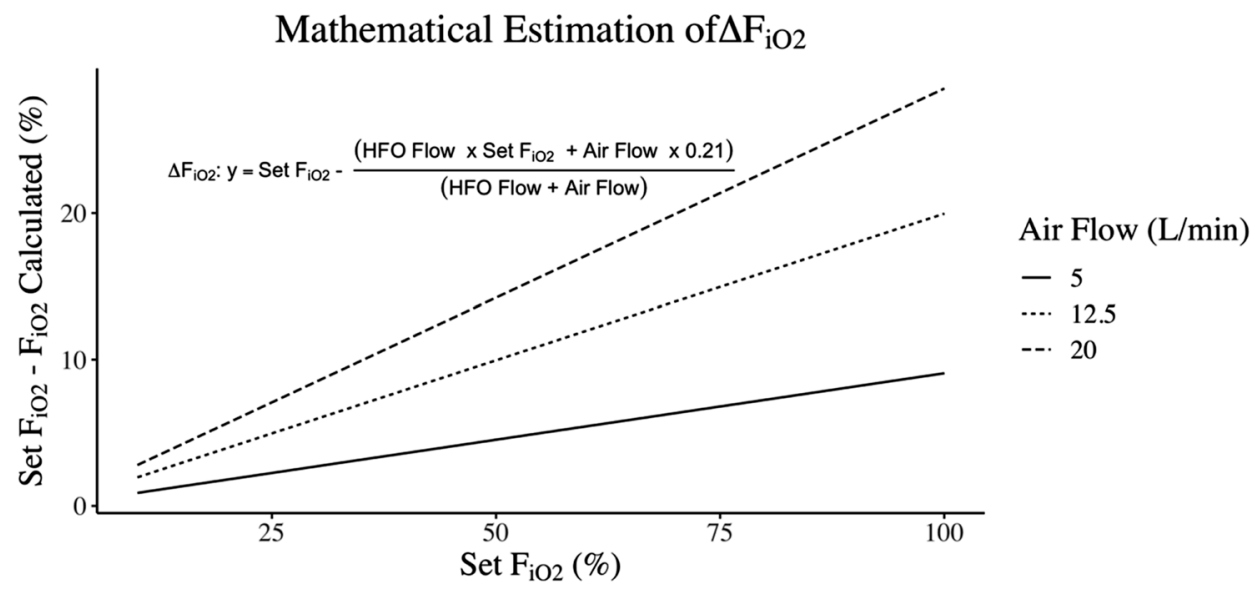

and set HFO Flow was of $13 \mathrm{~L} / \mathrm{min}$ in our experiment, we choose to represent Air Flows of 5, 12.5 and $20 \mathrm{~L} / \mathrm{min}$. In this simulation, we see that the lower $\mathrm{sF}_{\mathrm{iO} 2}$, the less it will be affected by room air blending, and thus, the difference in $\mathrm{SF}_{\mathrm{iO} 2}$ and calculated $\mathrm{F}_{\mathrm{iO} 2}$ will remain small. In the same way, the higher the Air Flow, the more air blending occurs, and thus, increasing difference between $\mathrm{sF}_{\mathrm{iO} 2}$ and calculated $\mathrm{F}_{\mathrm{iO} 2}$. This is in accordance with our findings that higher $\mathrm{sF}_{\mathrm{iO} 2}$ and lower HFO flows tend to augment $\Delta \mathrm{F}_{\mathrm{iO} 2}$.

Clinical applications of our findings are important. Indeed, how sicker the patients, the more important $\dot{V}_{\mathrm{I}}$ and the need of high $\mathrm{F}_{\mathrm{iO} 2}$, the less reliable $\mathrm{F}_{\mathrm{iO} 2}$ delivery from HFO become. The only parameter limiting differences in $\mathrm{sF}_{\mathrm{iO} 2}$ and actual $\mathrm{F}_{\mathrm{iO} 2}$ in patients with high $\dot{V}_{\mathrm{I}}$ seem to be the flow rate at HFO device. We could therefore suggest augmenting flow in these patients before trying to augment $\mathrm{F}_{\mathrm{iO} 2}$ to diminish room-air suction effect of patients with major peak inspiratory flow. The use of devices with the ability to deliver higher Flows could also be determinant in assuring reliable $\mathrm{F}_{\mathrm{iO} 2}$ to patients with high $\dot{V}_{\mathrm{I}}$.

Another objective of our study was to analyze the effect of the adjunction of a dead space in the circuit. The addition of a tube ISO 22 of $30 \mathrm{~cm}$ of length $(0.230 \mathrm{~L})$ on the T-piece did significantly decrease $\Delta \mathrm{F}_{\mathrm{iO} 2}$. This could be explained by the fact that during expiration, high oxygenated air from HFO will be contained in the dead spaces (mouth, surgical mask or Double Trunk Mask). According to the air-mixing theorem, during inspiration, with Inspiratory Flow above HFO Flow, instead of room air at a fraction of 0.21 of oxygen, air at higher oxygen fractions will blend with high oxygenated air from HFO, thus limiting $\Delta \mathrm{F}_{\mathrm{iO} 2}$. Hence, adjunction of a dead space (Double Trunk Mask or equivalent) could also be a promising premise to enhance HFO therapy as it was already clinically demonstrated $[13,14]$ and should be further studied.

The present study has limitations. In clinical practice it is difficult to appreciate actual $\dot{V}_{\mathrm{E}}$ and estimate the $\mathrm{T}_{\mathrm{i}}$ on total respiratory cycle time $\left(T_{i}+T_{e}\right)$ ratio which determine mean inspiratory flow and could help estimating peak inspiratory flow. Furthermore, as it is a bench study, the clinical consequences can only be hypothesized and warrant further in vivo research.

Our model does not exactly reproduce three-dimensional anatomy of the upper airways. Nevertheless, in physiological situation, we expect less ideal gas flows than our experimental design. Hence, we expect more turbulent flows in patient's upper airways, which only can augment our estimate $\Delta \mathrm{F}_{\mathrm{iO} 2}$ through amplifying air blending.

\section{Conclusion}

The present bench study did expose a weakness of HFO devices in reliability of delivering accurate effective inspired $\mathrm{F}_{\mathrm{IO} 2}$ at high $\dot{V}_{\mathrm{I}}$ as well as, to a lesser extent, at $\dot{V}_{\mathrm{I}}$ below equivalent HFO Flows. Moreover, set $\mathrm{HFO}$ flow and $\mathrm{sF}_{\mathrm{IO} 2}$ did influence variability of effective inspired oxygen fraction. Until further in vivo research of stability and reliability of effective inspired oxygen fraction during HFO treatment, we advocate to use $\mathrm{sF}_{\mathrm{IO} 2}$ with caution in severity scores and scores predicting the need for intubation.

Nevertheless, the adjunction of a dead space in the experimental set-up significantly amended variability between $\mathrm{sF}_{\mathrm{IO} 2}$ and effective inspired $\mathrm{F}_{\mathrm{iO} 2}$ and could thus be a promising start point to improve success rate of HFO therapy.

Author's contribution CT, FD, WP designed the study, acquired data and wrote the manuscript. Profs XW, GR, AS and GC wrote, read and approved the final manuscript. Drs CT, SM and VB have contributed to bench study conception and statistical calculation.

Funding The study did not receive any funds of any kind. 
Data availability The dataset used and analyzed during this study are available from the corresponding author on reasonable request.

\section{Declarations}

Conflict of interest None of the Authors have any potential conflict of interest related to the manuscript.

Ethical approval Not applicable.

Consent to participate Not applicable.

\section{References}

1. Ward JJ. High-flow oxygen administration by nasal cannula for adult and perinatal patients. Respir Care. 2013;58(1):98-120.

2. Nishimura M. High-flow nasal cannula oxygen therapy in adults. J Intensive Care. 2015;3(1):1-8.

3. Chikata Y, Onodera M, Oto J, Nishimura M. FIO2 in an adult model simulating high-flow nasal cannula therapy. Respir Care. 2017;62(2):193-8.

4. Nishimura M. High-flow nasal cannula oxygen therapy in adults: physiological benefits, indication, clinical benefits, and adverse effects. Respir Care. 2016. https://doi.org/10.4187/respcare. 04577.

5. Katz JA, Marks JD. Inspiratory work with and without continuous positive airway pressure in patients with acute respiratory failure. Anesthesiology. 1985;63(6):598-607.

6. Gattinoni L, Coppola S, Cressoni M, Busana M, Rossi S, Chiumello D. COVID-19 does not lead to a "Typical" acute respiratory distress syndrome. Am J Respir Crit Care Med. 2020;201(10):1299-300.

7. Mæhlen JO, Mikalsen R, Heimdal HJ, Rehn M, Hagemo JS, Ottestad W. Pre-hospital critical care management of severe hypoxemia in victims of Covid-19: a case series. Scand J Trauma Resusc Emerg Med. 2021;29(1):16.

8. L'Her E, Deye N, Lellouche F, Taille S, Demoule A, Fraticelli A, et al. Physiologic effects of noninvasive ventilation during acute lung injury. Am J Respir Crit Care Med. 2005;172(9):1112-8.

9. Vincent JL, Moreno R, Takala J, Willatts S, De Mendonca A, Bruining H, et al. The SOFA (Sepsis-related Organ Failure Assessment) score to describe organ dysfunction/failure. On behalf of the Working Group on Sepsis-Related Problems of the European Society of Intensive Care Medicine. Intensive Care Med. 1996;22(7):707-10.

10. Force ADT, Ranieri VM, Rubenfeld GD, Thompson BT, Ferguson $\mathrm{ND}$, Caldwell E, et al. Acute respiratory distress syndrome: the Berlin Definition. JAMA. 2012;307(23):2526-33.

11. Roca O, Caralt B, Messika J, Samper M, Sztrymf B, Hernández $\mathrm{G}$, et al. An index combining respiratory rate and oxygenation to predict outcome of nasal high-flow therapy. Am J Respir Crit Care Med. 2019;199(11):1368-76.

12. Goldberg S, Ollila HM, Lin L, Sharifi H, Rico T, Andlauer O, et al. Analysis of hypoxic and hypercapnic ventilatory response in healthy volunteers. PLoS One. 2017;12(1):e0168930.

13. Duprez F, Bruyneel A, Machayekhi S, Droguet M, Bouckaert Y, Brimioulle $S$, et al. The double-trunk mask improves oxygenation during high-flow nasal cannula therapy for acute hypoxemic respiratory failure. Respir Care. 2019;64(8):908-14.

14. Montiel V, Robert A, Robert A, Nabaoui A, Marie T, Mestre NM, et al. Surgical mask on top of high-flow nasal cannula improves oxygenation in critically ill COVID-19 patients with hypoxemic respiratory failure. Ann Intensive Care. 2020. https://doi.org/10. 1186/s13613-020-00744-x.

15. Guillaume DW, DeVries D. Ambient pressure air/oxygen blender. J Biomed Eng. 1992;14(2):153-6.

Publisher's Note Springer Nature remains neutral with regard to jurisdictional claims in published maps and institutional affiliations. 